\title{
Awakening in extracorporeal membrane oxygenation as a bridge to lung transplantation
}

\author{
Su Hwan Lee \\ Division of Pulmonary and Critical Care Medicine, Department of Internal Medicine, Severance Hospital, Yonsei University College of Medicine, Seoul, Korea
}

Although the rate of lung transplantation (LTX), the last treatment option for end-stage lung disease, is increasing, some patients waiting for LTx need a bridging strategy for LTx due to the limited number of available donor lungs. For a long time, mechanical ventilation has been employed as a bridge to LTx because the outcome of using extracorporeal membrane oxygenation (ECMO) as a bridging strategy has been poor. However, the outcome after mechanical ventilation as a bridge to LTx was poor compared with that in patients without bridges. With advances in technology and the accumulation of experience, the outcome of ECMO as a bridge to LTx has improved, and the rate of ECMO use as a bridging strategy has increased over time. However, whether the use of ECMO as a bridge to LTx can achieve survival rates similar to those of non-bridged LTx patients remains controversial. In 2010, one center introduced awake ECMO strategy for LTx bridging, and its use as a bridge to LTx has been showing favorable outcomes to date. Awake ECMO has several advantages, such as maintenance of physical activity, spontaneous breathing, avoidance of endotracheal intubation, and reduced use of sedatives and analgesics, but it may cause serious problems. Nonetheless, several studies have shown that awake ECMO performed by a multidisciplinary team is safe. In cases where ECMO or mechanical ventilation is required due to unavoidable exacerbation in patients awaiting LTx, the application of awake ECMO performed by an appropriately trained ECMO multi-disciplinary team can be useful.

Key Words: critical care; extracorporeal membrane oxygenation; lung transplantation

\section{INTRODUCTION}

Since the first successful lung transplantation (LTx) performed by Cooper in 1983, the number of lung transplants has increased to 69,000 over the past 30 years [1]. However, the number of donated lungs have been limited, and many patients with chronic respiratory failure requiring LTx were required to wait until they find a donor [2]. Unfortunately, some patients experience acute exacerbation of the underlying lung disease while awaiting LTx $[2,3]$.

For a long time, although patients who underwent LTx after receiving mechanical ventilation support had poorer outcomes than non-ventilated patients, invasive mechanical ventilation has mainly served as a bridge to LTx for LTx awaiting patients who experienced acute exacerbation of lung disease [4]. Owing to the advances in technology, extracorporeal membrane oxygenation (ECMO) has been introduced as a strategy to replace or support

\section{Review Article}

Received: January 11, 2022

Revised: February 10, 2022

Accepted: February 12, 2022

Corresponding author

Su Hwan Lee

Division of Pulmonary and Critical

Care Medicine, Department of Internal Medicine, Severance Hospital, Yonsei University College of Medicine, 50-1 Yonsei-ro, Seodaemun-gu, Seoul 03722, Korea

Tel: +82-2-2228-2273

Fax: +82-2-2228-2273

E-mail: hihogogo@yuhs.ac

Copyright (@) 2022 The Korean Society of Critical Care Medicine

This is an Open Access article distributed under the terms of Creative Attributions Non-Commercial License (https://creativecommons.org/li-censes/by-nc/4.0/) which permits unrestricted noncommercial use, distribution, and reproduction in any medium, provided the original work is properly cited. 
mechanical ventilation. The rate of ECMO use as a bridge to LTx has been increasing; some study reported that the survival outcome of LTx patients who used bridged ECMO was not inferior to that of non-bridged LTx patients [4].

Furthermore, as ECMO-related techniques and experience improved, the concept of "awake ECMO" was introduced [5]. During awake ECMO, patients breathe spontaneously without the support of a mechanical ventilator and remain awake [5]. The number of attempts of employing awake ECMO as part of ECMO management and the use of awake ECMO as a bridge to LTx is increasing. In this review article, we aimed to briefly discuss the outcomes and management of ECMO and awake ECMO as a bridge to LTx.

\section{HISTORY OF ECMO AND AWAKE ECMO}

Since the successful use of ECMO in patients with respiratory failure reported in 1971 [6], the first use of ECMO as a bridge to LTx was reported in 1978 by Toronto group [7]. A 19-yearold young patient with lung damage due to exposure to smoke during a fire incident experienced problems with oxygen supply to the lungs despite using mechanical ventilation; hence, he was oxygenated using an ECMO machine before and after LTx. Although the mechanical ventilator support and oxygen therapy were completely discontinued after LTx, the patient died 18 days after LTx due to bronchial dehiscence. Subsequently, in 1985, the same Toronto group reported the use of ECMO as a bridge to LTx in a 31-year-old patient with progressive respiratory failure due to paraquat poisoning. The patient underwent right LTx after bridging ECMO, and left LTx after bridging with ECMO due to graft failure of the right transplanted lung. After re-LTx, the transplanted organ showed good lung function; however, the patient died 93 days after the first LTx due to a cerebrovascular accident caused by tracheal innominate artery fistula [8]. Although ECMO appeared to be a feasible strategy for bridging to LTx in these cases, it was considered a relative contraindication to LTx in the 1970s and the 1980s due to poor perioperative outcomes and several complications [9]. In a large-scale analysis of the prognosis according to oxygen supply using mechanical ventilation alone and ECMO with mechanical ventilation, which was initially employed in 2010, ECMO did not show a good outcome [10]. However, as the experience and techniques of ECMO accumulated and the number of centers providing ECMO support increased, the outcomes of patients who require ECMO as a bridge to LTx have not been inferior to those of non-ECMO pa-

\section{KEY MESSAGES}

- Although the outcome of extracorporeal membrane oxygenation (ECMO) as a bridge to lung transplantation (LTx) is improving, whether it can achieve survival similar to that of non-bridged LTx patients remains controversial.

- Awake ECMO performed by a multidisciplinary team can be considered a bridge strategy for LTx as it has several advantages and is considered safe.

tients [11-13].

In 2010, one center introduced the use of veno-arterial (VA) ECMO as a bridging strategy to LTx during awake and spontaneous breathing to avoid the disadvantages and complications associated with intubation and prolonged mechanical ventilation [14]. During awake ECMO, the patients are not deeply sedated and maintain spontaneous breathing without mechanical ventilation [5].

\section{OUTCOME OF ECMO AS A BRIDGE TO LTX}

Many studies on ECMO as a bridge to LTx have been conducted in the last 10 years. Chiumello et al. [15] reviewed the 1-year survival rates of LTx patients with bridged ECMO in 14 studies between 2010 and 2014. In all cases, standard veno-venous (VV) ECMO or VA ECMO was used, and the bridging time before LTx ranged from a median of 3 to 16 days. Five studies reported survival rates of $50 \%$ to $70 \%$, four studies reported survival rates of $70 \%$ to $90 \%$, and two studies reported survival rates of up to $90 \%$ [15]. These studies showed that the survival rates were similar between the group using ECMO bridging and that using mechanical ventilation alone [15]. However, since the number of patients included in these studies did not exceed 50 and were heterogeneous according to the centers, it was not possible to confirm whether ECMO is a better bridging strategy to LTx than mechanical ventilation. However, what is clear, the survival rate of ECMO patients increased significantly over time, from $30 \%$ in 2005 to $75 \%$ in 2010 [16].

To overcome this limitation, Hayanga et al. [4] reported the results of a survival rate analysis using the United Network for Organ Sharing database for the period 2005-2017. A total of 21,576 transplant patients were analyzed by dividing them into no bridge $(n=19,783)$, mechanical ventilation $(n=1,129)$, and ECMO groups ( $\mathrm{n}=664)$. The survival rate of the ECMO bridging group significantly improved over time, and reached a similar 
level as that of the survival rate in the mechanical ventilation group. Similar results have been reported in other countries [17-19], and the ECMO strategy as a bridge to LTx has been accepted.

However, in a recent meta-analysis comparing non-bridged and ECMO-bridged LTx patients using 19 studies, non-bridged LTx patients showed better 1-year to 5-year survival rates and fewer complications compared with the ECMO-bridged LTx patients [20]. In summary, whether ECMO as a bridge to LT can achieve survival rates similar to those of non-bridged LTx patients remains controversial.

The number of patients awaiting LTx largely exceeds the number of available organs, resulting in long waiting times. A bridging strategy may be necessary if LTx is not contraindicated in patients with advanced respiratory failure. If the awaiting LTx candidates have no absolute contraindications to ECMO, a bridged ECMO strategy can be the last option during the waiting period. If the use of bridged ECMO cannot be avoided in awaiting LTx candidates, a management method is needed to lead it in a better direction.

The results of multivariate analysis in previous meta-analysis study showed that awake status (relative risk [RR], 2.7; 95\% confidence interval [CI], 1.29-5.65), extubated on ECMO (RR, 5.39; 95\% CI, 0.79-36), and ambulation (RR, 7.58; 95\% CI, 2.16-26.62) were predictors of successful bridge to LTx [20]. Consistent with these factors, several studies have reported positive results associated with the use of ECMO as a bridge to LTx, such as awakening, minimal sedation, spontaneous breathing, and physical activity during ECMO [11,16,21]. Over the years, the use of awake ECMO to avoid tracheal intubation and mechanical ventilation has gained popularity, becoming the preferred first-line approach for patients awaiting LTx.

\section{OUTCOME OF AWAKE ECMO AS A BRIDGE TO LTX}

Fuehner et al. [22] analyzed the prognosis of patients awaiting LTx using the data of 26 awake ECMO and 34 mechanical ventilation patients; this study was the first sizable series analysis of awake ECMO as a bridge to LTx. This study found that awake ECMO had been a successful bridge to LTx, resulted in the shorter duration of mechanical ventilation use after LTx, and had a significantly higher survival rate compared with mechanical ventilation alone ( $80 \%$ vs. $50 \%$ ) [22]. To overcome the small sample size, Schechter et al. [23] analyzed the survival rates according to the bridging type of 12,403 LTx patients from May 2005 to September 2013 using the United Network for Organ Sharing database. This study compared the survival rates of the awake ECMO, mechanical ventilation, ECMO with mechanical ventilation, and non-bridged LTx groups [23]. The 3-year survival rate after LTx in the awake ECMO group was significantly higher than that in the mechanical ventilation and ECMO with mechanical ventilation groups. When the awake group was compared with the non-bridged LTx group, the 1-year and 3-year survival rates of the awake ECMO group were $70.4 \%$ and $64.5 \%$, while those of the non-bridged LTx group were $84.2 \%$ and $67 \%$, respectively. Although the awake ECMO group had a worse 1-year survival rate compared with the non-bridged LTx group (70.4\% vs. $84.2 \%$, respectively), the mid-term survival of patients on ECMO alone was not significantly different $(\mathrm{P}=0.16)$ [23]. After adjustment using Cox analysis, the mortality risk in the awake ECMO group did not increase compared with that in the non-bridged LTx group $(\mathrm{P}=0.39)$. In 2019, Tipograf et al. [11] adjusted the baseline characteristics using propensity score matching between the awake ECMO and non-bridged LTx groups and reported that there was no difference in post-LTx survival rate between 70 awake ECMO patients and non-bridged LTx patients (log-rank $\mathrm{P}=0.53$ ). Furthermore, Kim et al. recently reported that the awake ECMO group showed increased ventilator-free days, decreased intensive care unit (ICU) length of stay, and higher gait ability and lung function after LTx compared with the nonawake ECMO group [24].

These results suggest that awake ECMO is a better strategy than sedated ECMO with mechanical ventilation while awaiting LTx and support the survival outcome results, which demonstrates that the post-transplant survival of awake ECMO patients is comparable to that of non-bridged patients.

\section{ADVANTAGES OF AWAKE ECMO}

One of the advantages of awake ECMO as a bridge to LTx was maintenance of physical activity (Table 1). In 2010, Garcia et al [25]. reported the possibility of physical activity in LTx patients waiting for awake ECMO. Even in healthy people, regardless of age, a 10-day bed rest induced muscle loss [26,27]. Moreover, a prospective study on critical illness myopathy showed that prolonged mechanical ventilation induced the occurrence of critical illness myopathy in more than $25 \%$ of ICU patients under mechanical ventilation [28]. Patients with critical illnesses awaiting LTx under mechanical ventilation may experience more rapid muscle loss. Active physical activity during critical 
Table 1. Advantages and disadvantages of awake ECMO

\begin{tabular}{|c|c|c|}
\hline Status & Advantage & Disadvantage \\
\hline Maintenance of physical activity & Maintain muscle mass and strength & Increase the risk of catheter dislocation \\
\hline \multirow[t]{3}{*}{ Spontaneous breathing } & Maintain respiratory muscle and diaphragm function & $\begin{array}{l}\text { Increase transpulmonary pressure and the risk of } \\
\text { ventilator-induced lung injury }\end{array}$ \\
\hline & Maintain the expansion of the chest wall and lungs & Increases oxygen consumption and $\mathrm{CO}_{2}$ production \\
\hline & Favor venous return and maintains cardiac filling & \\
\hline Avoiding intubation & Reduce the risk of ventilator-associated pneumonia & Sometimes emergency intubation may be required. \\
\hline \multirow{3}{*}{$\begin{array}{l}\text { Awake through reducing use of sedative and } \\
\text { analgesic }\end{array}$} & Reduce the risk of delirium & \multirow{3}{*}{ Increase pain, discomfort, and anxiety } \\
\hline & $\begin{array}{l}\text { Enhance communication between the medical staff and } \\
\text { the patient }\end{array}$ & \\
\hline & Allow participation in decision making & \\
\hline
\end{tabular}

ECMO: extracorporeal membrane oxygenation.

care is associated with improvement and maintenance of muscle strength [29]. The importance of physical activity through training for LTx candidates is already known [30].

Another advantage of awake ECMO is that spontaneous breathing induces the maintenance of respiratory muscle tone and diaphragm function [5,31]. Although spontaneous breathing may cause patient self-inflated lung injury (P-SILI) due to an increase in transpulmonary pressure owing to the exertion of vigorous effort, the effect of maintaining diaphragm function is greater than that of P-SILI in patients waiting for LTx as they have an end-stage lung disease. A previous prospective study showed that lung function could be improved by adding inspiratory muscle training to the standard pulmonary rehabilitation [32]. In another retrospective study comparing lung function 6 months after LTx according to the spontaneous breathing status of patients using ECMO as a bridge to LTx, the spontaneous breathing group showed higher lung function than the non-awake group [24].

Avoiding endotracheal intubation is also an advantage of awake ECMO. Prolonged use of endotracheal tubes can disrupt the natural defense barrier of the airway and increase the risk of pneumonia [33]. The most significant risk factor for hospital-acquired pneumonia is mechanical ventilation, and prolonged intubation increases the risk of ventilator-associated pneumonia [34]. These infections increase the risk of failure of bridges to LTx in patients with end-stage lung disease and increase the risk of mortality after LTx [35]. A study of awake ECMO as a bridge to heart transplantation showed a lower incidence of pneumonia compared to non-awake ECMO group [36].

At the time of intubation, patients may experience several complications, such as aspiration of gastric contents, vocal cord injury, laryngeal edema, pneumothorax, pneumomedi- astinum, hypoxemia due to esophageal intubation, and cardiac arrest [37]. Additionally, the use of an endotracheal tube increases the use of sedation and analgesics, which may cause side effects. The use of sedatives has been associated with delirium, a condition that reduces interactions with healthcare providers [5]. During awake ECMO, patients with spontaneous breathing, reduced sedative dose, and no delirium can ingest orally and have less ICU psychosis [24]. Furthermore, patients can communicate with the medical staff and participate in decision-making.

\section{AWAKE ECMO MANAGEMENT}

\section{Attempt of Using Awake ECMO}

The possibility of awake and spontaneous breathing in ECMO patients can be determined by several factors, including oxygen requirement, hypercapnia status, level of consciousness, underlying disease, and purpose of ECMO (Table 2) [38,39]. In some cases, ECMO cannulation was performed without intubation, and awake ECMO was initiated. In other studies, ECMO cannulation was inserted after intubation, mechanical ventilation was maintained, extubation was performed, and awake ECMO was initiated.

Physical activity can be attempted if the patient is hemodynamically stable, the cannulation position is stable, there is absence of bleeding at the cannulation site, the ECMO flow is stable, agitation is not observed, and anxiety is not observed, regardless of the ECMO type, including VV and VA [40,41]. A bicaval dual-lumen catheter is preferred over two independent cannulas at different venous insertion sites to allow the performance of physical activity during awake ECMO. However, physical activity can be performed even when two independent cannulas are inserted at different venous sites, including 
Table 2. Indications and contraindications of awake ECMO

\begin{tabular}{l}
\hline Awake ECMO \\
\hline Indication \\
Ability to protect airways \\
Low dose or no vasoactive requirement \\
No need for high PEEP \\
Contraindication \\
Hemodynamic unstable (high dose of vasoactive drugs) \\
Deep sedation and muscle relaxation (RASS 3-4) \\
Active bleeding \\
Malignant arrhythmia \\
Brain injury \\
Unstable blood flow mechanics \\
Unexpected high respiratory rate or severe anxiety \\
ECMO: extracorporeal membrane oxygenation; PEEP: positive end-expiratory \\
pressure; RASS: Richmond Agitation-Sedation Scale.
\end{tabular}

the femoral vein $[40,42]$.

During awake ECMO, use of sedatives and analgesics, including dexmedetomidine, remifentanil, and fentanyl, may help reduce pain and anxiety. Some patients may require additional oxygen supply using a high-flow nasal cannula and non-rebreather masks.

\section{Preparing and Monitoring during Physical Activity}

Hemodynamic monitoring in awake ECMO patients did not differ from that in general ICU patients on mechanical ventilation, including continuous monitoring of all vital signs. However, the flow of ECMO should be carefully monitored in awake ECMO patients because gas exchange mainly occurs with ECMO [43]. Cannula dislocation or flow disturbance can induce life-threatening conditions due to severe hypoxemia during awake ECMO [44]. During physical activity, the medical staff should be assess the cannulation sites, observe the movement of the cannula, and monitor for reduction in blood flow due to position changes. Although several problems may occur, a previous systemic review reported that passive and active physical therapy is safe when performed by a professional ECMO multidisciplinary team [42].

Patients must be connected to a monitoring device to checking their vital signs during physical activity. Any changes in the patients' vital signs should be noted in order to determine whether the physical activity should be continued. Patients may require increased ECMO blood flow or additional oxygen supply using a high-flow nasal cannula or mechanical ventilation during the performance of physical activities [45]. Additionally, fluid supplementation may be required to prevent chattering and to maintain the ECMO flow.

\section{Respiratory Management during Awake ECMO}

Respiratory rehabilitation before LTx can help maintain the respiratory muscle function, reduce the retention of secretions, and reduce the risk of postoperative complications [46]. Before the start of respiratory treatment, respiratory assessment including review of chest radiograph, airway status (tracheostomy status or not), movement of the chest wall and diaphragm, respiration rate, and lung sound should be performed. Furthermore, the cannula location, possible posture of patients, lung compliance, anticoagulation level, and cause of end-stage lung disease should be considered when selecting the respiratory therapy options for ECMO patients [44]. Respiratory management can be performed by positioning the patients for postural drainage, injection of saline via a closed suction port and suctioning, using manual or ventilator hyperinflation techniques, utilizing nebulizers, performing physiotherapy-assisted flexible bronchoscopy, ensuring intermittent positive pressure breathing, and using chest wall vibrator.

\section{Physical Activity}

Physical activity starts as a simple and passive activity and progresses to a more complex and active activity depending on the patient's condition. Patients can start bed activity, including passive range of motion to resistive training and limb exercise, and gradually increase the intensity of physical activities to cycling on bed, sitting on the edge of bed, standing next to the bed, and then ambulation [40]. Various equipment including bed bikes, chair pedals, standing frames, Zimmer frames, and tilt tables can be used. If a patient can walk in place with an assistant, walking around the ICU is possible with the assistance of appropriately trained ECMO multidisciplinary team members such as nurses, physical therapists, perfusionists, respiratory therapists, and intensivist.

\section{Nutrition}

Based on current research, enteral nutrition is safe and well tolerated in adults, regardless of the ECMO type [47-49]. Early enteral nutrition is not associated with harm during VV and VA ECMO [47]. A retrospective study of 1,769 patients under VA ECMO showed that early enteral nutrition was associated with a lower mortality rate compared with late enteral nutrition [48]. Provision of appropriate nutritional support is important for improving the patients' performance of physical activity; however, underfeeding is common in ECMO patients [49]. There- 
fore, the measurement or estimation of energy expenditure may be helpful in determining the proper caloric needs. However, as there are no currently available guidelines regarding the use of ECMO, it is reasonable to follow the current guidelines for critically ill patients until further research is available [47].

\section{Problem during Awake ECMO}

According to the level of consciousness and physical activities performed during ECMO, the patients may experience more problems, which were not considered in conventional ECMO (Table 3) [50]. The patients may experience increased $\mathrm{CO}_{2}$ production and require higher oxygen level as the work of breathing is increased. To overcome these problems, the medical staff should adjust the ECMO blood flow and sweep gas, and the patients can receive additional oxygen support using a high-flow nasal cannula. The patients may need to undergo tracheostomy to decrease the work of breathing and receive proper respiratory tract management.

Anxiety and agitation may induce vigorous effort, leading to a P-SILI and increase the work of breathing. Some drugs, including dexmedetomidine and remifentanil, may be helpful. Excessive cardiac output can lead to hypoxemia compared with ECMO flow-induced hypoxemia, and the administration of beta-blockers may help in relieving hypoxemia [51].

Sometimes, while maintaining spontaneous respiration and physical activity, ECMO flow reduction or chattering may be induced by inferior vena cava collapse [50,52]. Hypovolemia can be corrected with fluid therapy, and light sedation can help if the respiratory effort is excessive. Additionally, if the drain catheter is located in the femoral vein, the catheter tip can be moved down the diaphragm due to the movement of the leg. In this case, the location of the drain catheter may be adjusted or the ECMO flow may be lowered if oxygen saturation is maintained. Occasionally, chattering may occur because of bending, and the circuit line should be checked.

Sometimes, the patients may develop right-sided heart failure and eventually die during VV ECMO. Monitoring using echocardiography during ECMO helps detect biventricular size and function [52]. In right-sided heart failure case, another cannula should be added to the system for veno-arteriovenous ECMO or the oxy-right ventricular assist device to deliver blood to the arterial circulation in order to provide direct circulatory support [53].

Problems with ECMO machine operation, including catheter dislocation, de-cannulation, circuit rupture, and pump failure, can occur unexpectedly. In case of catheter dislocation, cannulation, or circuit rupture, the catheter should be clamped immediately, the pump should be turned off, help should be sought, and compress and intubation should be performed [50]. Circuit changes must be made while stabilizing the patients' vital signs. When the pump fails, it should be operated manually using a hand crake, and the cause must be corrected [50].

Table 3. Problems during awake ECMO

\begin{tabular}{|c|c|c|}
\hline Problem & Status of occurrence & Challenge to be solved \\
\hline \multirow[t]{3}{*}{ Hypoxemia } & $\begin{array}{l}\text { Increases oxygen consumption due to the } \\
\text { increased work of breathing }\end{array}$ & Adjustment of the ECMO flow \\
\hline & Difficulty removing secretions & Additional oxygen supply using HFNC and mask \\
\hline & & Tracheostomy \\
\hline \multirow[t]{2}{*}{ Anxiety and agitation } & $\begin{array}{l}\text { Discomfort due to the presence of devices and } \\
\text { lines }\end{array}$ & $\begin{array}{l}\text { Use of low-dose analgesics and sedative drugs } \\
\text { including dexmedetomidine and remifentanil }\end{array}$ \\
\hline & Increases the respiratory rate & Use of low-dose beta-blockers \\
\hline \multirow[t]{4}{*}{ Chattering of catheter } & Bending of circuit & Correction circuit \\
\hline & Hypovolemia & Fluid supply \\
\hline & Catheter tip migration due to activity & ECMO flow adjustment \\
\hline & & Catheter position adjustment \\
\hline $\begin{array}{l}\text { Progress right heart dysfunction or pulmonary } \\
\text { hypertension }\end{array}$ & In W ECMO & $\begin{array}{l}\text { Change to VAV ECMO or the oxy-right ventricular } \\
\text { assist device }\end{array}$ \\
\hline \multirow[t]{2}{*}{ Machine problem } & Catheter decannulation/circuit rupture & $\begin{array}{l}\text { Clamping the catheter, turning off the pump, } \\
\text { calling for help, compression, and intubation } \rightarrow \\
\text { Circuit change }\end{array}$ \\
\hline & Pump failure & $\begin{array}{l}\text { Operated manually using hand crake } \rightarrow \text { Correcting } \\
\text { the underlying cause or changing the machine }\end{array}$ \\
\hline
\end{tabular}

ECMO: extracorporeal membrane oxygenation; HFNC: high-flow nasal cannula; W: veno-venous; VAV: veno-arteriovenous 


\section{LIMITATION}

Aforementioned many studies showed successful awake ECMO as a bridge to LTx, however, there are still insufficient studies on failure rate of awake ECMO, rate of emergency intubation during awake ECMO, and unexpected complications and events during awake ECMO. Therefore, there may be bias, we should read careful about these paper.

\section{CONCLUSION}

With advances in ECMO technology, patients who were previously excluded from the transplant waiting list due to disease exacerbation can now be bridged with ECMO; as a result, the rate of ECMO use in patients awaiting LTx has increased. Although it remains controversial whether ECMO as a bridge to LTx can achieve similar outcomes as that in unbridged LTx patients, awake ECMO showed several benefits and favorable outcomes. In cases requiring ECMO or mechanical ventilation due to unavoidable exacerbation in awaiting LTx patients, awake ECMO strategy performed by an appropriately trained ECMO multi-disciplinary team can be useful compared with mechanical ventilation or conventional ECMO strategy.

\section{CONFLICT OF INTEREST}

No potential conflict of interest relevant to this article was reported.

\section{ORCID}

Su Hwan Lee

https://orcid.org/0000-0002-3487-2574

\section{REFERENCES}

1. Yeung JC, Keshavjee S. Overview of clinical lung transplantation. Cold Spring Harb Perspect Med 2014;4:a015628.

2. van der Mark SC, Hoek RA, Hellemons ME. Developments in lung transplantation over the past decade. Eur Respir Rev 2020;29:190132.

3. Mattar A, Chatterjee S, Loor G. Bridging to lung transplantation. Crit Care Clin 2019;35:11-25.

4. Hayanga JW, Hayanga HK, Holmes SD, Ren Y, Shigemura N, Badhwar V, et al. Mechanical ventilation and extracorporeal membrane oxygenation as a bridge to lung transplantation: closing the gap. J Heart Lung Transplant 2019;38:1104-11.
5. Langer T, Santini A, Bottino N, Crotti S, Batchinsky AI, Pesenti A, et al. "Awake" extracorporeal membrane oxygenation (ECMO): pathophysiology, technical considerations, and clinical pioneering. Crit Care 2016;20:150.

6. Hill JD, O’Brien TG, Murray JJ, Dontigny L, Bramson ML, Osborn JJ, et al. Prolonged extracorporeal oxygenation for acute post-traumatic respiratory failure (shock-lung syndrome): use of the Bramson membrane lung. N Engl J Med 1972;286:62934.

7. Nelems JM, Duffin J, Glynn FX, Brebner J, Scott AA, Cooper JD. Extracorporeal membrane oxygenator support for human lung transplantation. J Thorac Cardiovasc Surg 1978;76:28-32.

8. The Toronto Lung Transplant group. Sequential bilateral lung transplantation for paraquat poisoning: a case report. J Thorac Cardiovasc Surg 1985;89:734-42.

9. Maurer JR, Frost AE, Estenne M, Higenbottam T, Glanville AR. International guidelines for the selection of lung transplant candidates. Transplantation 1998;66:951-6.

10. Mason DP, Thuita L, Nowicki ER, Murthy SC, Pettersson GB, Blackstone EH. Should lung transplantation be performed for patients on mechanical respiratory support?: the US experience. J Thorac Cardiovasc Surg 2010;139:765-73.

11. Tipograf Y, Salna M, Minko E, Grogan EL, Agerstrand C, Sonett J, et al. Outcomes of extracorporeal membrane oxygenation as a bridge to lung transplantation. Ann Thorac Surg 2019;107:145663.

12. Oto T, Rosenfeldt F, Rowland M, Pick A, Rabinov M, Preovolos A, et al. Extracorporeal membrane oxygenation after lung transplantation: evolving technique improves outcomes. Ann Thorac Surg 2004;78:1230-5.

13. Lafarge M, Mordant P, Thabut G, Brouchet L, Falcoz PE, Haloun A, et al. Experience of extracorporeal membrane oxygenation as a bridge to lung transplantation in France. J Heart Lung Transplant 2013;32:905-13.

14. Olsson KM, Simon A, Strueber M, Hadem J, Wiesner O, Gottlieb J, et al. Extracorporeal membrane oxygenation in nonintubated patients as bridge to lung transplantation. Am J Transplant 2010;10:2173-8

15. Chiumello D, Coppola S, Froio S, Colombo A, Del Sorbo L. Extracorporeal life support as bridge to lung transplantation: a systematic review. Crit Care 2015;19:19.

16. Benazzo A, Schwarz S, Frommlet F, Schweiger T, Jaksch P, Schellongowski P, et al. Twenty-year experience with extracorporeal life support as bridge to lung transplantation. J Thorac Cardiovasc Surg 2019;157:2515-25.

17. Ko RE, Lee JG, Kim SY, Kim YT, Choi SM, Kim DH, et al. Extra- 
corporeal membrane oxygenation as a bridge to lung transplantation: analysis of Korean organ transplantation registry (KOTRY) data. Respir Res 2020;21:20.

18. Stącel T, Urlik M, Antończyk R, Latos M, Wiklińska A, Przybyłowski P, et al. Extracorporeal membrane oxygenation as a bridge to lung transplantation: first Polish experience. Transplant Proc 2020;52:2110-2.

19. Biscotti M, Gannon WD, Agerstrand C, Abrams D, Sonett J, Brodie D, et al. Awake extracorporeal membrane oxygenation as bridge to lung transplantation: a 9-year experience. Ann Thorac Surg 2017;104:412-9.

20. Wan X, Bian T, Ye S, Cai P, Yu Z, Zhu J, et al. Extracorporeal membrane oxygenation as a bridge vs. non-bridging for lung transplantation: a systematic review and meta-analysis. Clin Transplant 2021;35:e14157.

21. Lang G, Kim D, Aigner C, Matila J, Taghavi S, Jaksch P, et al. Awake extracorporeal membrane oxygenation bridging for pulmonary retransplantation provides comparable results to elective retransplantation. J Heart Lung Transplant 2014;33:126472.

22. Fuehner T, Kuehn C, Hadem J, Wiesner O, Gottlieb J, Tudorache I, et al. Extracorporeal membrane oxygenation in awake patients as bridge to lung transplantation. Am J Respir Crit Care Med 2012;185:763-8.

23. Schechter MA, Ganapathi AM, Englum BR, Speicher PJ, Daneshmand MA, Davis RD, et al. Spontaneously breathing extracorporeal membrane oxygenation support provides the optimal bridge to lung transplantation. Transplantation 2016;100:2699-704.

24. Kim NE, Woo A, Kim SY, Leem AY, Park Y, Kwak SH, et al. Longand short-term clinical impact of awake extracorporeal membrane oxygenation as bridging therapy for lung transplantation. Respir Res 2021;22:306.

25. Garcia JP, Iacono A, Kon ZN, Griffith BP. Ambulatory extracorporeal membrane oxygenation: a new approach for bridge-tolung transplantation. J Thorac Cardiovasc Surg 2010;139:e1379.

26. Kortebein P, Ferrando A, Lombeida J, Wolfe R, Evans WJ. Effect of 10 days of bed rest on skeletal muscle in healthy older adults. JAMA 2007;297:1772-4.

27. Dirks ML, Wall BT, van de Valk B, Holloway TM, Holloway GP, Chabowski A, et al. One week of bed rest leads to substantial muscle atrophy and induces whole-body insulin resistance in the absence of skeletal muscle lipid accumulation. Diabetes 2016;65:2862-75.

28. De Jonghe B, Sharshar T, Lefaucheur JP, Authier FJ, Du-
rand-Zaleski I, Boussarsar $\mathrm{M}$, et al. Paresis acquired in the intensive care unit: a prospective multicenter study. JAMA 2002;288:2859-67.

29. Tipping CJ, Harrold M, Holland A, Romero L, Nisbet T, Hodgson CL. The effects of active mobilisation and rehabilitation in ICU on mortality and function: a systematic review. Intensive Care Med 2017;43:171-83.

30. Hume E, Ward L, Wilkinson M, Manifield J, Clark S, Vogiatzis I. Exercise training for lung transplant candidates and recipients: a systematic review. Eur Respir Rev 2020;29:200053.

31. Yoshida T, Amato MB, Kavanagh BP, Fujino Y. Impact of spontaneous breathing during mechanical ventilation in acute respiratory distress syndrome. Curr Opin Crit Care 2019;25:192-8.

32. Pehlivan E, Mutluay F, Balcı A, Kılıç L. The effects of inspiratory muscle training on exercise capacity, dyspnea and respiratory functions in lung transplantation candidates: a randomized controlled trial. Clin Rehabil 2018;32:1328-39.

33. Hunter JD. Ventilator associated pneumonia. BMJ 2012;344: e3325.

34. Lynch JP 3rd. Hospital-acquired pneumonia: risk factors, microbiology, and treatment. Chest 2001;119(2 Suppl):373S-384S.

35. Lee JG, Park MS, Jeong SJ, Kim SY, Na S, Kim J, et al. Critical care before lung transplantation. Acute Crit Care 2018;33:197-205.

36. Deng L, Xia Q, Chi C, Hu G. Awake veno-arterial extracorporeal membrane oxygenation in patients with perioperative period acute heart failure in cardiac surgery. J Thorac Dis 2020;12:2179-87.

37. Griesdale DE, Bosma TL, Kurth T, Isac G, Chittock DR. Complications of endotracheal intubation in the critically ill. Intensive Care Med 2008;34:1835-42.

38. Crotti S, Bottino N, Ruggeri GM, Spinelli E, Tubiolo D, Lissoni A, et al. Spontaneous breathing during extracorporeal membrane oxygenation in acute respiratory failure. Anesthesiology 2017;126:678-87.

39. Ding L, He H. Awake extracorporeal membrane oxygenation for acute respiratory distress syndrome, details to be defined: who, when, and how? Crit Care Med 2019;47:e1038.

40. Wells CL, Forrester J, Vogel J, Rector R, Tabatabai A, Herr D. Safety and feasibility of early physical therapy for patients on extracorporeal membrane oxygenator: University of Maryland Medical Center experience. Crit Care Med 2018;46:53-9.

41. Pasrija C, Mackowick KM, Raithel M, Tran D, Boulos FM, Deatrick KB, et al. Ambulation with femoral arterial cannulation can be safely performed on venoarterial extracorporeal membrane oxygenation. Ann Thorac Surg 2019;107:1389-94.

42. Abrams D, Garan AR, Brodie D. Awake and fully mobile pa- 
tients on cardiac extracorporeal life support. Ann Cardiothorac Surg 2019;8:44-53.

43. Polastri M, Loforte A, Dell'Amore A, Nava S. Physiotherapy for patients on awake extracorporeal membrane oxygenation: a systematic review. Physiother Res Int 2016;21:203-9.

44. Eden A, Purkiss C, Cork G, Baddeley A, Morris K, Carey L, et al. In-patient physiotherapy for adults on veno-venous extracorporeal membrane oxygenation: United Kingdom ECMO Physiotherapy Network: a consensus agreement for best practice. J Intensive Care Soc 2017; 18:212-20.

45. Rickelmann C, Knoblauch DJ. Incorporating safe patient-handling techniques to mobilize our most complex patients on extra corporeal membrane oxygenation. Crit Care Nurs Q 2018;41:272-81.

46. Jang MH, Shin MJ, Shin YB. Pulmonary and physical rehabilitation in critically ill patients. Acute Crit Care 2019;34:1-13.

47. Bear DE, Smith E, Barrett NA. Nutrition support in adult patients receiving extracorporeal membrane oxygenation. Nutr Clin Pract 2018;33:738-46.

48. Ohbe H, Jo T, Yamana H, Matsui H, Fushimi K, Yasunaga H.
Early enteral nutrition for cardiogenic or obstructive shock requiring venoarterial extracorporeal membrane oxygenation: a nationwide inpatient database study. Intensive Care Med 2018;44:1258-65.

49. MacGowan L, Smith E, Elliott-Hammond C, Sanderson B, Ong D, Daly K, et al. Adequacy of nutrition support during extracorporeal membrane oxygenation. Clin Nutr 2019;38:324-31.

50. Patel B, Arcaro M, Chatterjee S. Bedside troubleshooting during venovenous extracorporeal membrane oxygenation (ECMO). J Thorac Dis 2019;11(Suppl 14):S1698-707.

51. Bunge JJ, Diaby S, Valle AL, Bakker J, Gommers D, Vincent JL, et al. Safety and efficacy of beta-blockers to improve oxygenation in patients on veno-venous ECMO. J Crit Care 2019;53:248-52.

52. Douflé G, Roscoe A, Billia F, Fan E. Echocardiography for adult patients supported with extracorporeal membrane oxygenation. Crit Care 2015;19:326.

53. Bunge JJ, Caliskan K, Gommers D, Reis Miranda D. Right ventricular dysfunction during acute respiratory distress syndrome and veno-venous extracorporeal membrane oxygenation. J Thorac Dis 2018;10(Suppl 5):S674-82. 